\title{
LENGUAS E IMÁGENES EN LA CARTELERÍA COMERCIAL: CONCURRENCIAS EN UN PAISAJE LINGÜÍSTICO ARGENTINO
}

\author{
Yolanda Haydee Hipperdinger \\ Universidad Nacional del Sur, CONICET, Argentina
}

\section{RESUMEN}

En este artículo examinamos la cartelería comercial de la ciudad de Bahía Blanca, en el área dialectal bonaerense del español de la Argentina. Nos ocupamos, en particular, de la que corresponde a establecimientos comerciales en cuyas denominaciones se ha eludido el uso del espańol, comunicativamente hegemónico en esa área, y se ha optado en cambio por recurrir a otras lenguas. Analizamos las preferencias evidenciadas en este último sentido en el paisaje lingüístico de la ciudad y, conjuntamente, analizamos por qué tipos de imágenes son acompañadas esas denominaciones comerciales en la correspondiente cartelería. La clasificación de las imágenes que proponemos se basa en su relación con las denominaciones referidas, con el origen nacional o cultural de la lengua de la que provienen y con el rubro de los establecimientos, y constituye un aporte transferible al estudio de cualesquiera otros paisajes lingüísticos.

Palabras Clave: paisaje lingüístico, cartelería comercial, elecciones lingüísticas marcadas, imágenes.

\author{
LANGUAGES AND IMAGES IN THE COMMERCIAL SIGNAGE:
} CONCURRENCES IN AN ARGENTINE LINGUISTIC LANDSCAPE

\section{Abstract}

In this paper we examine the commercial signage of the city of Bahía Blanca, in the Buenos Aires Spanish dialectal area of the Argentina. We deal, in particular, with the one corresponding to ventures in whose denominations the use of Spanish -the communicatively hegemonic language in the area- has been avoided, and the productors have preferred to turn to other languages. We analyze the tendencies evidenced in this last sense in the linguistic landscape of the city and, simultaneously, we examine by what types of images these commercial denominations are accompanied in the corresponding signage. The classification of the images that we propose is based on their relationship with the denominations referred to, with the national or cultural origin of the language they come from and with the ventures' specialty, and can be transferable to the study of any other linguistic landscapes. KEYWORDs: linguistic landscape, commercial signage, marked linguistic choices, images. 


\section{INTRODUCCIÓN}

Un innovador campo de las investigaciones sobre el lenguaje, notoriamente dinámico y en plena expansión, lo constituye el estudio del denominado linguistic landscape o paisaje lingüístico, esto es, el estudio de la escritura expuesta en el espacio público (v. e.g. Ben-Rafael, Shohamy y Barni 2010: xiv; Van Mensel, Vandenbroucke y Blackwood 2016: 423).

Este campo de indagaciones ha tenido como interés primario, desde el aporte inaugural de Landry y Bourhis (1997) que lo estableció como tal, la investigación de la presencia relativa de lenguas coexistentes ${ }^{1}$. Esa presencia ha sido tomada principalmente como indicadora de la vitalidad de grupos etnolingüísticos convivientes, en situaciones de contacto lingüístico directo, y como indicadora de valoraciones socialmente sostenidas, en situaciones de contacto lingüístico indirecto.

Con esa distinción se imbrica otra, también corrientemente implicada en los estudios sobre paisaje lingüístico: la diferenciación entre las elecciones lingüísticas vinculadas con decisiones oficiales, y expuestas en ese ámbito, y las que corresponden al ámbito privado y obedecen a los imperativos ideológico-lingüísticos de los hablantes mismos (que pueden, incluso, enfrentar decisiones oficiales). Empleando una extendida metáfora de orientación espacial, las elecciones de uno y otro tipo son por lo general referidas como adoptadas en dirección top-down o desde arriba y bottom-up o desde abajo, respectivamente (v. e.g. Leimgruber 2019)2.

En este último sentido, una conclusión común a estudios desarrollados sobre el paisaje lingüístico de ciudades de muy diversos lugares del mundo, en relación con las elecciones operadas desde abajo, es la llamativa presencia del inglés, la lengua que Calvet (1999) ha conceptualizado como «hipercentral», aunque el inglés no sea vehículo de comunicación ordinaria de ninguno de los grupos humanos convivientes: en las elecciones lingüísticas que se exhiben en la cartelería comercial, la recurrencia al inglés es un recurso empleado con frecuencia en la publicitación de bienes y servicios que se pretende mostrar como actuales y/o de circulación y estándares de calidad internacionales (v. e.g. Schlick 2003) ${ }^{3}$.

En la intersección del interés por las elecciones lingüísticas desde abajo y por las que implican la recurrencia a lenguas que no se encuentran en contacto directo, numerosas investigaciones han venido centrándose en entornos sociolingüísticos

${ }^{1}$ Muy en especial, estas exploraciones se han desarrollado en entornos urbanos. Por esa circunscripción -que ha sido superada, no obstante, en algunos estudios (como el de Fernández Juncal 2019) - también se habla de linguistic cityscape (v. e.g. Rusnaningtias 2019).

2 Por un detalle de la composición de cada conjunto puede verse la contribución señera de Ben-Rafael, Shohamy, Hasan Amara y Trumper-Hecht (2006: 14).

${ }^{3}$ Esto vale tanto para el paisaje lingüístico como para la publicidad gráfica en revistas y periódicos, como lo ejemplifican, para el mundo hispánico, los trabajos de Benítez Sierra (2014) y Robles Ávila (2014) en España, Gerding Salas, Fuentes Morrison y Kotz Grabole (2012) en Chile, Delgado Álvarez (2005) en Costa Rica o Reyes Padilla (2005) en Perú. En los que llamó «rótulos publicitarios», esa presencia del inglés fue abordada ya en el artículo - precursor de los estudios del paisaje lingüístico- de Medina López (1991). 
que manifiestan la hegemonía comunicativa de una única lengua (Martínez Ibarra 2016: 137) y, en particular, en el paisaje lingüístico de conglomerados urbanos «que se tienen como prototípicamente monolingües» en los que, no obstante, «también hacen aparición otros idiomas» (Pons Rodríguez 2011: 102). En esa línea de investigaciones, se ha dedicado una atención especial a «la rotulación comercial (donde se usan [por ejemplo] inglés, francés o italiano con propósito connotativo)» (ibid.). Así, la cartelería comercial y, sobre todo, las denominaciones escogidas para los establecimientos, han sido objeto de estudio en ciudades de ubicaciones territorialmente distantes y situaciones sociolingüísticas diversas, como lo ejemplifican los estudios de Wang (2013), Amer y Obeidat (2014), Prapobratanakul (2016) y Shang y Guo (2016).

El presente artículo se enmarca en la misma intersección de intereses y toma como objeto de estudio la cartelería que exhibe denominaciones comerciales en un espacio público urbano de la Argentina: el de la ciudad de Bahía Blanca, ubicada en la región sudoeste de la provincia de Buenos Aires ${ }^{4}$, reiteradamente considerada referencial respecto del español bonaerense (desde los destacados estudios de Fontanella de Weinberg, i.a. 1979a) en indagaciones dialectológicas y sociolingüísticas. El paisaje lingüístico de la ciudad muestra contemporáneamente características comunes con otras ciudades globalizadas, en el marco de un empleo comunicativo hegemónico - al igual que en el conjunto de la región correspondiente- del español (v. infra). Nos centraremos, por ello, en las denominaciones comerciales formuladas total o parcialmente en otras lenguas, que destacan sobre ese «fondo» al constituir elecciones lingüísticas marcadas ${ }^{5}$.

La recurrencia a otras lenguas en tales denominaciones ha merecido ya atención en estudios previos sobre Bahía Blanca (Hipperdinger 2018; Oostdyk y Zangla 2019). Esos estudios, que por un lado han mostrado una decidida preferencia comparativa por el inglés, por otro lado han explorado la distribución del conjunto de las lenguas escogidas de acuerdo con los distintos rubros comerciales. Tomando esas investigaciones como punto de partida, en este artículo nos ocuparemos de analizar el modo en que las denominaciones comerciales en otras lenguas son presentadas en la cartelería, atendiendo en particular a las imágenes que las acompañan: asumimos que el interés por la dimensión espacial del lenguaje no puede excluirlas, en la medida en que no solo concurren con las emisiones lingüísticas en el espacio público, sino que también colaboran con ellas en cuanto a los fines. Coincidimos en tal sentido con importantes estudiosos, como Shohamy y Gorter (2009), que entienden que unas y otras forman igualmente parte del objeto de estudio del paisaje lingüístico:

${ }^{4}$ Bahía Blanca se ubica a unos $700 \mathrm{~km}$ al sur de la Ciudad Autónoma de Buenos Aires, capital de la Argentina. Al momento de la realización del último Censo Nacional, en 2010, la población de la ciudad era de 301572 habitantes.

5 La concepción implicada aquí, de una elección lingüística como no marcada si es socialmente esperable y como marcada en caso contrario, proviene de la «teoría de la marcación» formulada por Myers-Scotton (1993a et alibi). 
It is the attention to language in the environment, words and images displayed and exposed in public spaces, that is the center of attention in this rapidly growing area, referred to as linguistic landscape (Shohamy y Gorter 2009: 1).

En relación con la decisión expuesta, propondremos en primer lugar una clasificación de las imágenes que aparecen en la cartelería en concurrencia con denominaciones comerciales no españolas, y exploraremos seguidamente las relaciones entre las categorías resultantes y las diferentes lenguas implicadas en la onomástica correspondiente.

\section{LENGUAS Y PAISAJE EN BAHÍA BLANCA}

Bahía Blanca fue fundada en 1828, como un fuerte en el marco del enfrentamiento que la organización estatal llevó adelante contra la población indígena y que dio lugar al proceso conocido con el nombre -hoy tan cuestionado como el propio enfrentamiento- de "Conquista del Desierto». En ese marco, la recepción de población inmigratoria fue impulsada desde las etapas fundacionales, por lo que el componente inmigratorio ocupó un lugar crucial en la composición poblacional de la ciudad (v. Monacci 1988). Hasta la década de 1960, entre los inmigrantes primaron los de procedencia europea (v. e.g. Fontanella de Weinberg 1979b), muy en especial durante la etapa de modernización del país que se extendió entre 1880 y 1930, décadas en las que la inmigración fue, según la calificación de Romero (1963), «aluvial». Bahía Blanca recibió entonces un elevado porcentaje, principalmente, de inmigración italiana; esa colectividad, cuyo aporte alcanzó al 20\% en 1914, se constituyó, por amplia diferencia, en la primera no hispanoparlante a nivel local. La recepción de inmigración descendió notoriamente tras ese período, y desde la década de 1970 ha consistido prioritariamente en el ingreso de inmigración no europea, proveniente sobre todo de países limítrofes y, en la actualidad, también de origen asiático y africano (aunque de modo cuantitativamente irrelevante). La investigación desarrollada sobre la inmigración más reciente es aún escasa ${ }^{6}$, pero en cambio han sido extensamente estudiados el aporte «aluvial» y el proceso de homogeneización lingüística operado con el generalizado desplazamiento de las lenguas de origen, que volvió hegemónico el uso comunicativo del español en el conjunto de la región?

${ }^{6}$ Por el momento, solamente se han desarrollado estudios sobre cuestiones ideológico-lingüísticas relativas a la inmigración de países limítrofes (a nivel endo- y exogrupal), que implican la valoración del portugués brasileńo y de las lenguas indígenas habladas por los inmigrantes y/o en su región de procedencia (Orsi 2013, entre otros), y sobre el proceso de mantenimiento y cambio de una de las lenguas de que se trata (el quechua), en el caso de la inmigración boliviana (Toranzos 2014).

7 Entre los estudios desarrollados sobre el desplazamiento lingüístico se destaca el de Fontanella de Weinberg (1979b). Una panorámica sobre la investigación pertinente puede consultarse en Hipperdinger (2016). 
Como manifestación de esa hegemonía, el paisaje lingüístico de Bahía Blanca, cuyo estudio se ha iniciado recientemente, pero cuenta ya con importantes avances, es comunicativamente monolingüe en español. No obstante, evidencia la «aparición de otros idiomas [...] con propósito connotativo» antes señalada (Pons Rodríguez 2011: 102), como rasgo común con otras ciudades globalizadas.

Los avances aludidos incluyen un primer acercamiento a las decisiones tomadas desde arriba, en el caso de las denominaciones de las vías de circulación (Campetella 2019), y una descripción general, en el marco de las decisiones tomadas desde abajo, de qué lenguas son empleadas en el ámbito comercial, con qué frecuencia y en qué rubros ${ }^{8}$, con atención especial a las denominaciones de los comercios mismos. Entre las denominaciones de vías de circulación y de comercios enfocadas en esas indagaciones puede trazarse una diferencia de importancia (que se vincula con la de autoría, sin coincidir con ella) de acuerdo con las motivaciones de la recurrencia a lenguas diferentes del español. Por un lado, en el caso de las elecciones operadas desde arriba, la recurrencia a otras lenguas es el resultado de decisiones que no obedecen de manera primaria a razones lingüísticas. Así, el homenaje a personas ilustres, que frecuentemente orienta la onomástica referida, ha dado como resultado la inscripción en el espacio público de formas reconociblemente exógenas, pero la decisión oficial de que calles bahienses se llamen Brown, Ricchieri, Rondeau, Karakachoff, Van Hees o Túpac Amaru (por citar solo unos pocos ejemplos) ha sido tomada sobre la base de la voluntad de homenajear a los portadores de esos antropónimos, con independencia de su procedencia lingüística. Por otro lado, en las elecciones operadas desde abajo priman las que, en oposición, pueden considerarse decisiones lingüísticas propiamente dichas: siendo el español la lengua de uso hegemónico, nada obliga en principio a los productores a hacer elecciones divergentes, ni sus decisiones en tal sentido son, por lo tanto, consecuencia de otras.

Solo unas pocas excepciones han sido señaladas en relación con esto último: la reproducción estricta de la denominación de una cierta marca de productos, en el caso de franquicias comerciales, y la configuración exógena del apellido del propietario, así como la del nombre de la calle o del barrio en el que se ubica el local comercial, que se verifican con cierta frecuencia en la onomástica respectiva (v. Hipperdinger 2018: 204). En estos casos, el arbitrio de los productores se ha ejercido en la determinación de qué vender y en la de usar como denominación comercial -frente a otras opciones- un apellido o un topónimo vinculados con la propiedad o la ubicación del establecimiento, pero no en relación con la lengua en la que se formula la denominación de la marca, ni con la lengua de origen del apellido o el topónimo. Tales decisiones, por lo mismo, se vinculan más con las oficiales antes comentadas

${ }^{8}$ Además de los estudios pertinentes previamente referidos, se cuenta entre estos últimos el desarrollado por Duché Mónaco et al. (2019), que incluye el abordaje del uso de piezas léxicas y sintagmas de otras lenguas (tanto con mayor o menor «necesidad» cuanto con mayor o menor «fidelidad" a la lengua de origen) en el centro de la ciudad y en un perímetro circunvalatorio alejado de él, en comercios de distintos rubros, así como una comparación particular de ese uso en negocios de venta de indumentaria con clientelas de distinto poder adquisitivo. 
que con las decisiones de llamar Candy Land a un negocio de venta de golosinas, Aloha a una lencería o Wayna a una tienda de indumentaria femenina (por limitarnos, nuevamente, a unos pocos ejemplos). Paralelamente, no siempre las franquicias comerciales son desarrollos locales de empresas que no lo son, dado que también hay casas matrices locales, y en las denominaciones correspondientes pueden asimismo distinguirse las que recuperan antropónimos o topónimos (como la cadena internacional Mc Donald's y la agencia de viajes London) de las que llevan nombres «creativos» (como la marca de indumentaria Footy, especializada en calzado).

Por consiguiente, entendemos que la diferencia fundamental que corresponde trazar entre las denominaciones escogidas comentadas, tanto para las operadas desde arriba como para las operadas desde abajo, es la que separa a las que recuperan los que pueden reconocerse como nombres propios con precedencia a su empleo en tales denominaciones de las que, en cambio, otorgan ese carácter a cualquier otro nombre o construcción por implicarlos en la onomástica referida. Es fácilmente apreciable la existencia de denominaciones de ambos tipos en el paisaje lingüístico bahiense, en la esfera oficial oponiendo casos como los de Brown, Ricchieri, Rondeau, Karakachoff, Van Hees o Túpac Amaru a los de las calles bahienses llamadas Fortinero, El resero, Las toscas, Las acacias, Gorriones o Las golondrinas (también, solo por ejemplo), y en la esfera privada oponiendo denominaciones como las de los locales de la cadena $M c$ Donald's, o las de la farmacia Di Nucci y la cerrajería Brown (referidos en Hipperdinger 2018: 204), a casos como los anteriormente aludidos de Candy Land, Aloha o Wayna.

Las consideraciones expuestas conducen a otra observación de importancia sobre las elecciones lingüísticas implicadas en las denominaciones de vías de circulación y de establecimientos comerciales de Bahía Blanca: a través de la revisión de la totalidad de las elecciones denominativas referidas tomadas desde arriba en la ciudad, hemos podido constatar que las que no se reducen a la recuperación de nombres propios previos se limitan, en cambio, a formulaciones en español, en coincidencia con lo que llevamos dicho sobre la hegemonía comunicativa de esta lengua; por el contrario, no se limitan a formulaciones en español las elecciones denominativas tomadas desde abajo.

Los estudios previos realizados en la ciudad sobre estas últimas denominaciones en lenguas diferentes del español (todos los cuales excluyeron de su consideración las que se reducían a marcas, topónimos y antropónimos ${ }^{10}$ ) han mostrado la presencia de un amplio abanico de lenguas en la escritura públicamente exhibida, aunque sin recurrencia destacable salvo en pocos casos; los datos muestran una pre-

\footnotetext{
${ }_{9}$ Las denominaciones de las vías de circulación de la ciudad pueden consultarse en https:// www.bahia.gob.ar/calles/.

${ }^{10}$ Esa decisión, tomada principalmente en consideración de la imposibilidad de traducción y compatible con la argumentación recién presentada, es frecuente entre los estudiosos del paisaje lingüístico (v. e.g. Franco-Rodríguez 2009: 9, Coluzzi 2012: 229); algunos autores han defendido, en cambio, la conveniencia de su inclusión, en especial a partir de consideraciones sobre la percepción de su eventual «extranjeridad» por parte de los hablantes (v. Edelman 2009).
} 
ferencia decidida por el «hipercentral» inglés, seguido de lejos por muy pocas otras lenguas europeas y una única lengua americana: el italiano y el francés principalmente (y en ese orden), en el primer caso, y el mapudungún en el segundo. Las lenguas europeas referidas han sido en su momento lenguas inmigratorias en la región, y hoy son prestigiosas lenguas de difusión internacional a las que se puede acceder por vía escolar (v. Bein 2012: 111 ss.), y el mapudungún es la lengua del grupo etnolingüístico indígena de mayor importancia regional. En otras palabras, los productores tienden a elegir lenguas que pueden suponer que los potenciales destinatarios reconocerán, aun si no conocen lo suficiente de ellas como para comprender el significado de las expresiones lingüísticas concretas de que se trata, lo cual se vincula de modo directo con el propósito connotativo antes aludido: lo que parece importar centralmente es lo que la lengua misma puede evocar. Esa evocación, a su vez, tiene como condición de posibilidad el sostenimiento social de asociaciones estereotípicas, de naturaleza simbólica (v. e.g. Scollon y Wong Scollon 2003: 119), que es justamente lo que muestran los estudios citados al ponderar la distribución de las preferencias lingüísticas por rubros: el inglés invoca la «novedad» (por lo que es la única otra lengua usada en algunos comercios, como los dedicados a la tecnología de comunicaciones, y solamente no aparece en relación con productos considerados telúricos y/o autóctonos, rubros en los que se privilegia la recurrencia al mapudungún), el francés el «refinamiento» (sobre todo femenino) y el italiano la «elegancia» (sobre todo masculina); es frecuente también que se emplee el italiano en relación con productos reconocidos como del mismo origen (en especial pizzas y pastas, de consumo muy difundido en la región), para sugerir «autenticidad» respecto de su elaboración.

Los resultados de la investigación precedente, que alcanzan para dar cuenta de las preferencias aludidas, no solo revisten un interés intrínseco: habilitan además un interrogante en relación con la funcionalidad específica de las imágenes, ya que, si es razonable suponer que constituyen «ayudas» de los productores para orientar la interpretación de las elecciones lingüísticas marcadas, es razonable asimismo suponer que se acompasarán con ellas de modos peculiares discernibles. Es sobre la base de ese interrogante que diseñamos la investigación cuyo desarrollo y resultados se sintetizan en este artículo, que se centra en las imágenes observables en la cartelería con el doble objetivo, adelantado en la Introducción, de clasificarlas y de analizar su distribución según las lenguas que han sido empleadas en las denominaciones comerciales a las que acompañan.

\section{CONFORMACIÓN DEL CORPUS}

Comenzamos por conformar un cuerpo de datos sobre las denominaciones comerciales de Bahía Blanca en las que se recurre a una lengua diferente del español, registrando paralelamente las imágenes presentes en la cartelería. De acuerdo con lo expuesto supra, y en consonancia con los trabajos previos sobre el paisaje lingüístico de la ciudad, decidimos excluir del estudio al que nos referimos seguidamente las denominaciones coincidentes con marcas internacionales o Big Commer- 
cial Names (v. Ben-Rafael y Ben-Rafael 2019), así como con topónimos-mayores y menores-y antropónimos - nombres de pila sin otro uso, apellidos-. Además, se tuvo en cuenta que las emisiones reconocibles como no españolas pertenecieran efectivamente a alguna otra lengua, aun cuando hubieran sufrido adaptaciones u otras formas de alteración en su escritura (esto es, que no se tratara de «invenciones» ad hoc).

Para conformar ese corpus revisamos, por una parte, la cartelería de los establecimientos comerciales que se ubican en tres reconocidos conjuntos de ellos, todos con acceso centralizado y amplia recepción de visitantes: la (única) terminal de ómnibus de Bahía Blanca y dos de los principales enclaves comerciales de la ciudad: Galería Plaza y Bahía Blanca Plaza Shopping, el más tradicional y el más moderno (respectivamente) de los paseos de compras locales. Por otra parte, procedimos a una búsqueda de Google para identificar establecimientos comerciales en un amplio abanico de rubros (todos los abarcados por los centros mencionados), usando para la búsqueda siempre el mismo esquema: "X Bahía Blanca» (e.g. «Indumentaria femenina Bahía Blanca", "Indumentaria masculina Bahía Blanca», etc.); a la ubicación por vía virtual de estos establecimienos siguió -como en el caso de los centros referidos- el registro, en la cartelería correspondiente, de los datos a considerar en el análisis ${ }^{11}$.

A través de la combinación de ambos procedimientos, identificamos un total de 190 locales comerciales con denominaciones formuladas en lenguas diferentes del español, a las que se recurre con la desigual frecuencia que muestra la tabla $1^{12}$ :

\begin{tabular}{cc}
\hline TABLA 1 & \\
\hline LeNGUAS & $\begin{array}{c}\text { CANTIDAD DE } \\
\text { DENOMINACIONES }\end{array}$ \\
\hline Inglés & 104 \\
\hline Italiano & 40 \\
\hline Francés & 16 \\
\hline Mapudungún & 9 \\
\hline Griego & 4 \\
\hline Alemán & 3 \\
\hline Euskera & 3 \\
\hline Latín & 3 \\
\hline Náhuatl & 3 \\
\hline
\end{tabular}

11 La ubicación por vía virtual de los establecimientos comerciales (limitada a la primera pantalla de selecciones, cuando el resultado de la búsqueda arrojó más de una) fue realizada en los primeros días del mes de junio de 2018. La constatación de la exhibición de los datos referidos en este trabajo fue realizada entre junio y julio de ese año.

${ }_{12}$ Los resultados del cómputo se ordenan de mayor a menor. Cuando se trata de igual número, el orden es alfabético (lo mismo vale para las tablas de la sección 5.). 


\begin{tabular}{cc|}
\hline Árabe & 1 \\
\hline Hawaiano & 1 \\
\hline Portugués & 1 \\
\hline Quechua & 1 \\
\hline Sánscrito & 1 \\
\hline Total & 190 \\
\hline
\end{tabular}

En la cartelería de esos establecimientos se constata, junto a las denominaciones comerciales, una variada gama de «acompañamientos»: precisiones acerca del rubro, frases ponderativas, marcas registradas de los productos que se ofrecen y (lo que aquí nos interesa en particular) imágenes. Esas imágenes varían, en su grado de iconicidad, desde estilizadas representaciones esquemáticas hasta reproducciones fotográficas, pero no es en ese rango de variación en el que nos centraremos: lo haremos, en cambio, en la relación (igualmente variable) que las imágenes establecen con las denominaciones comerciales escogidas, las lenguas que han sido empleadas y el rubro de los establecimientos.

\section{LAS IMÁGENES Y SU CLASIFICACIÓN}

Como lo ha señalado Goddard para los avisos publicitarios en la prensa gráfica, también en el caso de la cartelería comercial «readers do not simply read images in isolation from the verbal text that accompanies them; nor do they read the verbal text without reference to accompanying images» (Goddard 2002: 13).

Explorando esa cooperación, encontramos que las imágenes suelen referirse a las denominaciones comerciales a las que acompañan, invocando en ocasiones la procedencia de la lengua empleada, pero que también pueden no vincularse con ellas sino solo con el rubro, en establecimientos cuyas denominaciones no lo hacen. A partir de esas exploraciones, elaboramos la clasificación que sigue:

a) Imágenes que se encuentran en relación sinonímica con las denominaciones comerciales de que se trata: el recurso iconográfico sirve como representación visual del significado de la emisión, al cual puede decirse que "traduce». Así, por ejemplo, la cartelería del cotillón Carrousel incluye la imagen de uno, y la de la tienda de artículos regionales Pehuen incluye la imagen de la conífera correspondiente ${ }^{13}$. Esa relación sinonímica puede establecerse incluso con sintagmas creativos, de propósitos lúdicos, como la denominación de la casa de fiestas Festival planet, que remite al nombre del canal televisivo Animal planet: en la correspondiente cartelería, la denominación aparece

13 En la variedad bonaerense del español, el equivalente de la palabra francesa carrousel es calesita y el de la palabra mapuche pehuen (o pehuén) es araucaria. 
acompañada por la imagen de un círculo sobre el que se ubican las siluetas de un niño pequeño que lleva globos consigo, otro mayor y un adulto, como representación de la evolución de la vida ${ }^{14}$ en un planeta cuyo carácter festivo queda indicado por los globos.

b) Imágenes que se encuentran en relación sinecdótica con el significado de la emisión respectiva, como la de una rosa en la cartelería de la florería The garden (con un vínculo de parte a todo con el significado de la emisión) o (en el sentido inverso) la de espigas de cereal en la cartelería de la panadería Boulangerie.

c) Imágenes que conducen a interpretaciones no literales de (parte de) las emisiones, como la de un flamenco en la cartelería de la cadena gastronómica Ave Caesar, especializada en platos elaborados con pollo: sobre la base de la homografía, el saludo latino puede también leerse como palabra espańola a partir de la indicación provista por la imagen del flamenco, que -como el pollo con el que se elaboran los platos- es un ave ${ }^{15}$.

d) Imágenes cuya relación con la emisión es indirecta o connotativa (a diferencia de los casos anteriores, que implican la denotación), como la de un refulgente sol que despunta incluida en la cartelería de la confitería Happiness.

e) Imágenes que no se relacionan con las denominaciones en otras lenguas, sino con las lenguas mismas. Es el caso de las imágenes de banderas, que remiten al origen territorial de la lengua implicada y funcionan, por lo tanto, metonímicamente. Lo ejemplifican la bandera italiana en la fábrica de pastas Nunzio y la bandera vasca en la tienda de especias Txapela ${ }^{16}$. Una variante del mismo recurso, para invocar un origen no territorial sino cultural, puede apreciarse por ejemplo en la imagen de un quincunce, que remite a las culturas ancestrales mesoamericanas, en la cartelería de la tienda que comercializa vegetales de cultivo orgánico La Tonantzin ${ }^{17}$.

f) Imágenes que no guardan relación con el significado de la denominación ni la lengua escogidas aunque sí, y de modo directo, con el rubro del esta-

${ }^{14}$ Es esta la temática prioritaria del canal aludido, que la aborda desde una perspectiva filogenética; la evolución representada en la imagen, en cambio, corresponde a una perspectiva ontogenética.

${ }^{15}$ En rigor, la imagen comentada (que se ve en la fotografía 3) es la única que encontramos en nuestro corpus con el valor referido. La estrategia seguida en la formulación de la denominación, en cambio, la encontramos también en la denominación de la zapatería Lemon pie; en este caso, la homografía interlingüística explotada lúdicamente es la que se da entre la forma inglesa pie $\leftrightarrow /$ par/ y la española pie $\leftrightarrow /$ pje/, siendo esta última y no la primera la que se relaciona con el rubro del establecimiento comercial.

16 En la cartelería de Txapela, palabra que significa «boina» en euskera, se incluye también (además de la bandera vasca, junto a la cual se ha ubicado la argentina) la imagen del sonriente rostro de un hombre que luce una.

${ }_{17}$ Este último establecimiento comercial, además, es el único de la muestra que expone en su cartelería la que puede considerarse una traducción stricto sensu de la denominación escogida: debajo de La Tonantzin se lee, en referencia a la deidad azteca, «Nuestra Venerable Madre Tierra» (v. fotografía 5). 
blecimiento, como las de artículos de librería y bazar que acompañan a la denominación del polirrubro ${ }^{18}$ Cash.

g) Imágenes que solo guardan relación con el rubro del establecimiento, pero de modo indirecto. Son imágenes de este tipo las representaciones asociadas a la femineidad -largas cabelleras, mariposas, flores, etc.- que reiteradamente acompañan a las denominaciones de tiendas de indumentaria y lencería para mujer, como Try me o Petit Paris ${ }^{19}$.

Las fotografías de las páginas siguientes ejemplifican los diversos tipos de imágenes que proponemos distinguir, según lo que hemos expuesto.

\section{5. ¿QUÉ IMÁGENES PARA QUÉ LENGUAS?}

La tabla 2 muestra, sobre el número total de imágenes que registramos (75), la cantidad que corresponde a cada uno de los tipos descriptos supra:

\begin{tabular}{cc}
\hline & TABLA 2 \\
\hline Tipo De IMAGen & CANTIDAD De IMÁGenes \\
\hline (a) & 19 \\
\hline (b) & 18 \\
\hline (c) & 1 \\
\hline (d) & 4 \\
\hline (e) & 6 \\
\hline (f) & 17 \\
\hline (g) & 10 \\
\hline Total & 75 \\
\hline
\end{tabular}

Como puede verse, las imágenes de los tipos (a), (b) y (f) lideran (en ese orden) las preferencias, con una diferencia de importancia, además, respecto de las que las siguen en cuanto a presencia relativa.

En la tabla 3, por otro lado, discriminamos las imágenes según la lengua a la que se ha recurrido en la denominación comercial correspondiente:

18 En español bonaerense se denominan multikioscos o polirrubros (a veces, como se ve en la fotografía 6 , con empleo de $<$ r $>$ en lugar de $<$ rr $>$ en la escritura) los comercios que venden golosinas y cigarrillos (como los kioscos) pero también, en combinaciones diversas, productos típicamente comercializados en negocios especializados: artículos de librería, juguetería, perfumería o bazar.

${ }_{19}$ En relación con el criterio de selección empleado en el relevamiento, cabe señalar que esta última denominación comercial incluye un topónimo, pero no se reduce a él: se usa el francés (petit) para calificar «algo francés» (París). Es de notar también que, curiosamente, el topónimo ha sido adaptado al español mediante la incorporación de la tilde, ausente en francés (v. fotografía 7). 


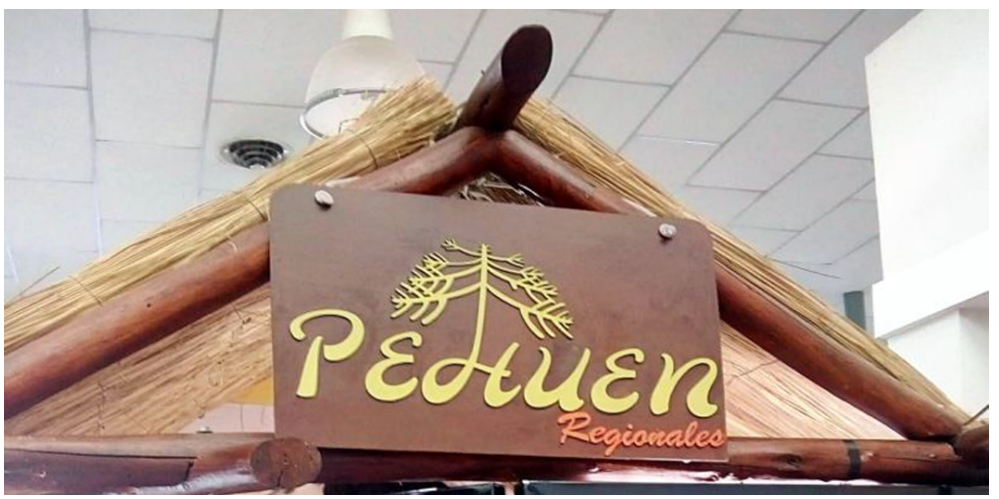

Fotografía 1. Ejemplo de imagen del tipo (a).

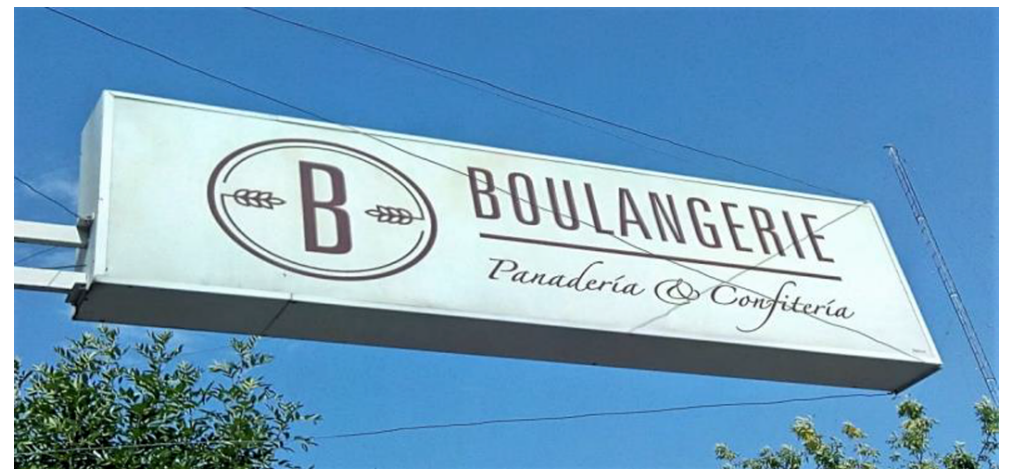

Fotografía 2. Ejemplo de imagen del tipo (b).

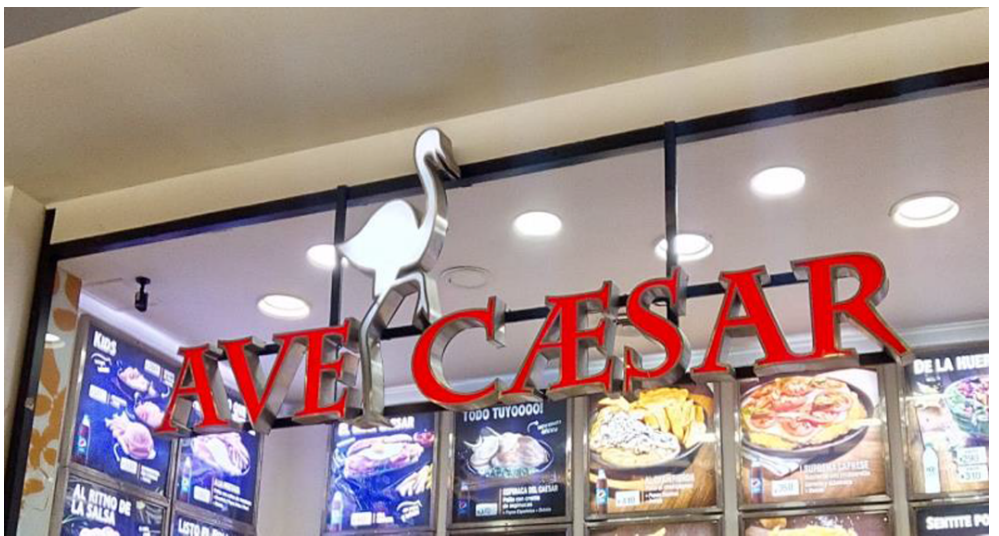

Fotografía 3. Ejemplo de imagen del tipo (c). 


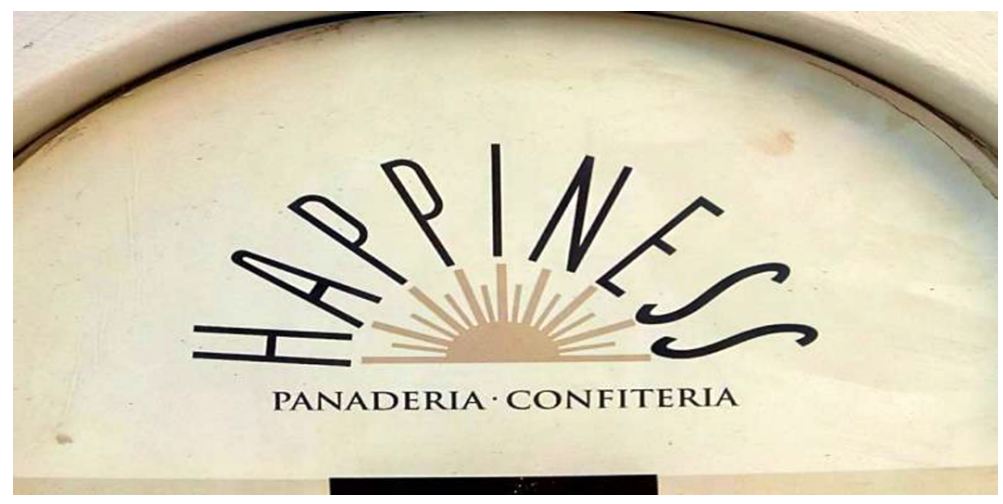

Fotografía 4. Ejemplo de imagen del tipo (d).

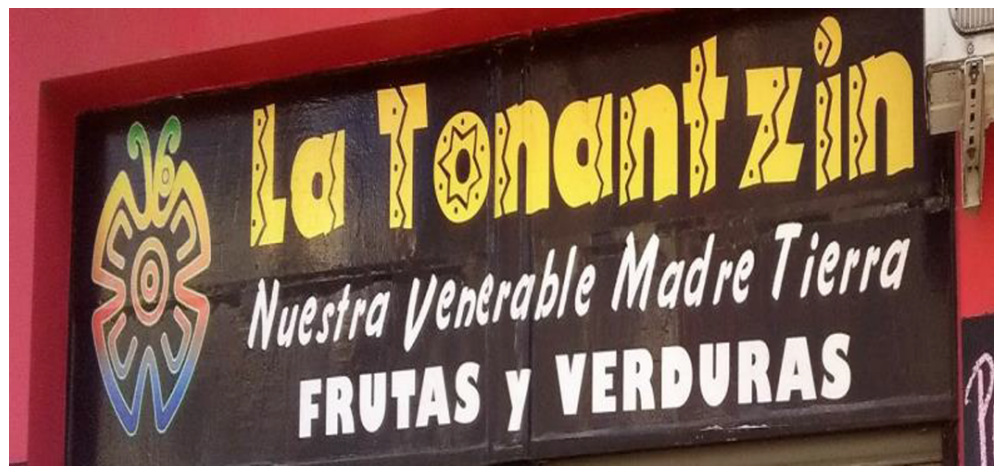

Fotografía 5. Ejemplo de imagen del tipo (e).

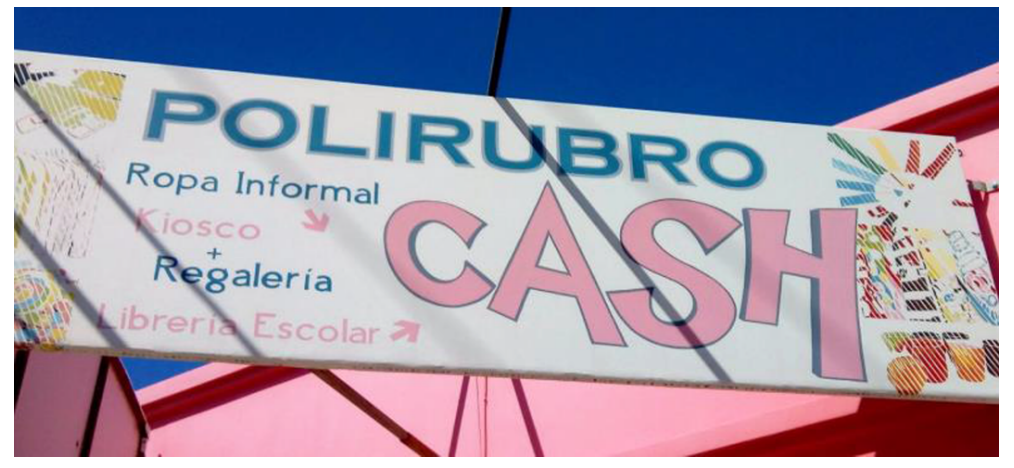

Fotografía 6. Ejemplo de imagen del tipo (f). 


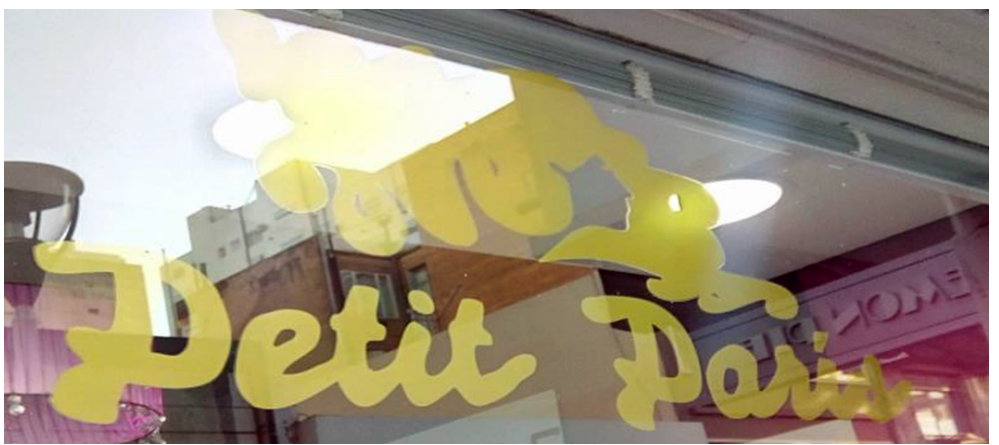

Fotografía 7. Ejemplo de imagen del tipo (g).

\begin{tabular}{cc}
\hline & TABLA 3 \\
\hline LeNGUAS & CANTIDAD DE IMÁGENES \\
\hline Inglés & 33 \\
\hline Italiano & 14 \\
\hline Francés & 8 \\
\hline Mapudungún & 7 \\
\hline Euskera & 4 \\
\hline Náhuatl & 3 \\
\hline Latín & 2 \\
\hline Árabe & 1 \\
\hline Griego & 1 \\
\hline Quechua & 1 \\
\hline Sánscrito & 1 \\
\hline Total & 75 \\
\hline
\end{tabular}

Según se aprecia, no se registran imágenes junto a las denominaciones comerciales formuladas en algunas de las lenguas detalladas en la tabla 1 (alemán, hawaiano y portugués). Sin embargo, puede observarse una consistencia general entre la tabla 1 y la 3: solo superan las cinco ocurrencias (que tomaremos como "piso" para distinguir las lenguas de uso recurrente o $\mathrm{no}^{20}$ ) formulaciones en cuatro lenguas, que son las mismas a las que anteriormente nos referimos; el conjunto de

${ }^{20}$ Por la arbitrariedad inherente a cualquier decisión de esta naturaleza, imprescindible sin embargo toda vez que los datos se cuantifican, remitimos a las consideraciones de Myers-Scotton (1993b: 207). 
las denominaciones que hacen uso de esas cuatro lenguas conforma casi el 90\% del total, y a ese conjunto le corresponde a su vez más del $80 \%$ de las imágenes registradas. El detalle respectivo es el siguiente:

\begin{tabular}{|c|c|c|}
\hline \multicolumn{3}{|c|}{ TABLA 4} \\
\hline Lenguas & CANTIDAD DE DENOMINACIONES & Cantidad de imágenes \\
\hline Inglés & 104 & 33 \\
\hline Italiano & 40 & 14 \\
\hline Francés & 16 & 8 \\
\hline Mapudungún & 9 & 7 \\
\hline
\end{tabular}

De la tabla 4, no obstante, se desprende una diferencia en la frecuencia con la que se «ilustran» las denominaciones en cada una de esas lenguas: en la escala gradual que en tal sentido puede trazarse, en un polo se ubican las denominaciones en las que se recurre al inglés, de las que solo un tercio concurre con imágenes, y en el otro las denominaciones en las que se recurre al mapudungún, que casi siempre lo hacen.

Ahora bien, ¿ hay igualmente tendencias preferenciales en el tipo de imágenes que acompañan a las denominaciones en las diferentes lenguas? La tabla siguiente sugiere que sí.

\begin{tabular}{|c|c|c|c|c|c|c|c|c|}
\hline \multicolumn{9}{|c|}{ TABLA 5} \\
\hline Lenguas & $\begin{array}{l}\text { IMÁGENES } \\
\text { TIPO (A) }\end{array}$ & $\begin{array}{c}\text { IMÁGENES } \\
\text { TIPO (B) }\end{array}$ & $\begin{array}{l}\text { IMÁGENES } \\
\text { TIPO (c) }\end{array}$ & $\begin{array}{l}\text { IMÁGENES } \\
\text { TIPO (D) }\end{array}$ & $\begin{array}{l}\text { IMÁGENES } \\
\text { TIPO (E) }\end{array}$ & $\begin{array}{l}\text { IMÁGENES } \\
\text { TIPO (F) }\end{array}$ & $\begin{array}{l}\text { IMÁGENES } \\
\text { TIPO (G) }\end{array}$ & TотAL \\
\hline Inglés & 8 & 10 & & 2 & & 9 & 4 & 33 \\
\hline Italiano & 2 & 3 & & 2 & 1 & 3 & 3 & 14 \\
\hline Francés & 2 & 2 & & & & 2 & 2 & 8 \\
\hline Mapudungún & 5 & 2 & & & & & & 7 \\
\hline Euskera & 1 & & & & 2 & 1 & & 4 \\
\hline Náhuatl & 1 & & & & 2 & & & 3 \\
\hline Latín & & & 1 & & & 1 & & 2 \\
\hline Árabe & & & & & & & 1 & 1 \\
\hline Griego & & & & & & 1 & & 1 \\
\hline Quechua & & & & & 1 & & & 1 \\
\hline Sánscrito & & 1 & & & & & & 1 \\
\hline Total & 19 & 18 & 1 & 4 & 6 & 17 & 10 & 75 \\
\hline
\end{tabular}

La distribución que muestra la tabla 5 permite diversas observaciones de importancia. En primer lugar, y nuevamente en lo que atañe a las cuatro lenguas a las que se recurre con más frecuencia, puede notarse una diferencia entre ellas según el mayor o menor equilibrio de su asociación con dos grupos de imágenes: las más 
estrechamente ligadas a las emisiones, i.e. las de los tipos (a) y (b), y las que no se ligan a ellas, i.e. los tipos (f) y (g). En tal sentido, el mayor equilibrio se observa en relación con denominaciones que hacen uso del francés; es similar el caso de las que recurren al italiano, y también se aprecia un relativo equilibrio cuando las denominaciones implican la recurrencia al inglés. En cambio, las denominaciones que hacen uso del mapudungún son acompañadas exclusivamente por imágenes de los primeros tipos -y, especialmente, del tipo (a)-.

En segundo lugar, es de señalar que las imágenes que acompañan a las denominaciones en las restantes lenguas, a las que raramente se recurre, solo se concentran en un caso: la casi totalidad de las imágenes de tipo (e), i.e. las que remiten al origen de la lengua empleada, acompañan a denominaciones en estas lenguas de empleo infrecuente.

Por último, es evidente que algunos tipos de imágenes son claramente preferidos, como lo muestra la preponderancia registrada para las de los tipos (a), (b) y (f), que pueden considerarse agrupados por su «literalidad», ya que no implican juego ni indirección de ninguna clase -a diferencia, respectivamente, del tipo (c) y del conjunto de los tipos (d), (e) y (g)-. Además, se observa priorizada la «ilustración» de las denominaciones comerciales elegidas, si bien esta preferencia debe ponderarse a la luz del hecho de que las denominaciones suelen vincularse con el rubro.

Por otra parte, la distribución de los tres tipos de imágenes favoritos según la lengua de la denominación a la que acompañan no muestra disimetrías notorias en el caso de las lenguas de uso recurrente, con la excepción del mapudungún. Lo muestra la tabla 6, en la que se han incorporado los porcentajes correspondientes:

\begin{tabular}{ccccc}
\hline \multicolumn{5}{c}{ TABLA 6 } \\
\hline \multirow{2}{*}{ LeNGUA } & $\begin{array}{c}\text { IMÁGENES } \\
\text { TIPO (A) }\end{array}$ & $\begin{array}{c}\text { IMÁGENES } \\
\text { TIPO (B) }\end{array}$ & $\begin{array}{c}\text { IMÁGENES } \\
\text { TIPO (F) }\end{array}$ & TotAL \\
\hline \multirow{2}{*}{ Inglés } & 8 & 10 & 9 & 33 \\
& $(24.24 \%)$ & $(30.30 \%)$ & $(27.27 \%)$ & $(100 \%)$ \\
\hline \multirow{2}{*}{ Italiano } & 2 & 3 & 3 & 14 \\
& $(14.29 \%)$ & $(21.43 \%)$ & $(21.43 \%)$ & $(100 \%)$ \\
\hline \multirow{2}{*}{ Francés } & 2 & 2 & 2 & 8 \\
& $(25.00 \%)$ & $(25.00 \%)$ & $(25.00 \%)$ & $(100 \%)$ \\
\hline \multirow{2}{*}{ Mapudungún } & 5 & 2 & & 7 \\
& $(71.43 \%)$ & $(28.57 \%)$ & & $(100 \%)$ \\
\hline
\end{tabular}

Las observaciones que realizamos sobre la cartelería comercial de Bahía Blanca, así, conducen a concluir que hay tendencias entre los usuarios tanto respecto de qué lenguas usar en las denominaciones comerciales, si deciden no usar el español, cuanto respecto de qué tipo de imágenes elegir para acompañarlas.

De acuerdo con lo expuesto en el apartado 2, las lenguas más frecuentemente elegidas son las más probablemente reconocibles: las lenguas europeas de que se trata han sido lenguas inmigratorias en la región (particularmente, en la ciudad, el italiano) y gozan de un prestigio ligado a su difusión internacional (máxima en el caso del inglés), que se vincula a su vez con la posibilidad de acceso a ellas que 
es ofrecida por vía académica; la única lengua americana empleada con cierta frecuencia, por otra parte, es la lengua de la población indígena de mayor importancia regional. Esto último separa al mapudungún de las demás lenguas americanas, y puede vincularse con que -a diferencia de lo observado en relación con denominaciones que recurren al náhuatl o al quechua- los productores prescindan de imágenes de tipo (e) para acompañar denominaciones en mapudungún.

La cartelería de establecimientos con denominaciones que recurren al mapudungún se distinguen, a su vez, de la que muestra recurrencias al inglés, el italiano o el francés, ya que las imágenes que las acompañan son casi siempre del tipo (a), en el primer caso, mientras que en los demás se distribuyen de modo más equilibrado entre los tipos preferidos. Al respecto, merece ante todo reflexión el hecho de que la preferencia en cuanto a las imágenes tienda a la «literalidad». En ese sentido, y si -como también dijimos- puede suponerse el reconocimiento de las lenguas preferidas, pero no su conocimiento, entendemos que:

a) la excepcionalidad de las imágenes de tipo (c) es previsible, ya que para poder jugar tiene que ser accesible -como en el caso de Ave Caesar-la clave del juego ${ }^{21}$;

b) es igualmente previsible que sea rara la apelación a la connotación, implicada en las imágenes de tipo (d), en la medida en que esta última supone el conocimiento del significado de las formas correspondientes ${ }^{22}$;

c) lo mismo puede decirse de las imágenes de tipo (e), ya que la invocación del origen de la lengua es «redundante» si se sabe de qué lengua se trata;

d) por último, puede considerarse esperable que si la imagen no remite a la denominación lo haga al rubro de modo directo, y no indirecto como en el tipo $(\mathrm{g})$, ya que ello aumenta la probabilidad de que esa (única) relación sea patente para los destinatarios.

Ahora bien, si la elección de las imágenes que acompañan a las lenguas preferidas siempre tiende a la «literalidad», las que acompañan a denominaciones en mapudungún parecen requerirla en su máximo grado. Creemos que ello puede ponerse en relación con que se trata de la lengua reconocible menos probablemente conocida (no tiene el prestigio ni la difusión de las lenguas europeas referidas y no forma parte de la oferta de la educación formal local): el ofrecimiento de una «traducción» anticipa (y suple) ese desconocimiento altamente probable. Obviamente, esta última no es la única funcionalidad posible de las imágenes de tipo (a) -ni de las de tipo (b), que también atienden a la denotación-, ya que puede registrárselas

${ }^{21}$ En este caso, el juego es posibilitado tanto por la proximidad formal entre el latín y el espańol, debida al parentesco, como por la aparición de la forma de saludo latina en producciones fílmicas y televisivas, que vuelve previsible que se la conozca como tal. Desde este último punto de vista, el caso se equipara al de otros relevados, como los de Aloha y Namasté, que comentamos infra.

${ }_{22}$ No es casual, por lo mismo, que las únicas denominaciones que encontramos acompañadas por ese tipo de imágenes hayan sido formuladas en las dos lenguas de uso más extendido, después del español, en el paisaje lingüístico local. 
igualmente acompañando denominaciones que no presentan problemas de inteligibilidad para destinatarios hispanohablantes, como el dibujo del rostro de un pirata (pañuelo en la cabeza, parche sobre un ojo) que acompaña a la denominación de la pizzería Il pirata. Sin embargo, es la única manera no lingüística de ofrecer una traducción, y por ende la mejor en la que una imagen puede anticipar la pregunta del destinatario por el significado de una emisión.

En los casos en los que el reconocimiento de la lengua no puede darse por supuesto, por otro lado, suele ser el caso que los productores puedan sin embargo confiar en el (re)conocimiento de la forma misma que han elegido. Son ejemplos la denominación comercial de la lencería Aloha, que recupera un saludo hawaiano probablemente conocido para los destinatarios por su difusión en películas, series y documentales, o la de la tienda de regalos Namasté, que recupera una expresión del sánscrito difundida a través de la práctica del yoga. No es este el caso, en cambio, de ninguna de las denominaciones comerciales en las cinco lenguas de uso más recurrente, lo cual engrosa la línea que separa a unas de otras como opciones posibles para la onomástica comercial.

En relación con las cuatro lenguas más empleadas, por último, volvemos a la observación que realizamos sobre los resultados expuestos en la tabla 4: las denominaciones que hacen uso del mapudungún, la lengua cuyo conocimiento (por las razones antes aludidas) es menos accesible para el conjunto de los destinatarios potenciales, son las más frecuentemente acompañadas por imágenes; de manera especular, las denominaciones formuladas en inglés, la lengua «hipercentral» que es la única incorporada de modo obligatorio a la educación primaria básica (Bein 2012: 120121) -y que, por lo tanto, es presumiblemente la más conocida-, son las menos frecuentemente acompañadas por imágenes.

\section{CONCLUSIONES Y PROYECCIONES}

La exposición que acabamos de presentar ha mostrado el valor heurístico de la clasificación funcional, que propusimos, de las imágenes que concurren con denominaciones comerciales en lenguas diferentes de la comunicativamente hegemónica. Esperamos que pueda ser aplicada asimismo a paisajes lingüísticos urbanos de otras radicaciones, para poner a prueba su exhaustividad.

En cuanto a los resultados puntuales, hemos mostrado que la distribución de las distintas clases de imágenes se muestra sensible al grado de familiaridad presumible de los destinatarios con las elecciones lingüísticas correspondientes. En tal sentido, una observación de importancia, en relación con las lenguas recurrentemente implicadas en la onomástica comercial de Bahía Blanca, es que la lengua menos usual es la que más imágenes convoca, mientras que la más usual es la que se presenta en una cartelería menos "ilustrada». Asimismo, en el primer caso las imágenes se vinculan solamente con la denotación de las emisiones lingüísticas, mientras que el empleo de imágenes que no lo hacen es de alta frecuencia en los restantes casos.

Consideramos que estas observaciones generales, así como las de mayor detalle que hemos realizado, abren interesantes posibilidades para exploraciones de 
enfoque comparativo dentro del área dialectal del español bonaerense, que permitan verificar coincidencias y diferencias tanto respecto del paisaje lingüístico de ciudades más grandes y cosmopolitas (principalmente, Buenos Aires) como respecto del de localidades con menor población, mayor vinculación con la vida rural y composición de la inmigración diferente de la descripta para Bahía Blanca (como en el caso de Coronel Suárez, ciudad sudbonaerense en la que el aporte inmigratorio dominante ha sido de habla alemana). Es por esta vía comparativa, que permitirá verificar cuánto hay de global y cuánto de local en el paisaje lingüístico estudiado, por la que prevemos continuar nuestras investigaciones.

Recibido: diciembre de 2019; ACEPTADo: abril de 2020 


\section{BIBLIOGRAFÍA}

Amer, Faten y Rasha Obeidat (2014): «Linguistic Landscape: A Case Study of Shop Signs in Aqaba City, Jordan", Asian Social Science 10 (18): 246-252. URL: http://www.ccsenet.org/journal/index.php/ass/article/view/39803; 08/10/2019.

BeIn, Roberto (2012): La politica lingüistica respecto de las lenguas extranjeras en la Argentina a partir de 1993 (tesis de doctorado), Wien: Universitat Wien. URL: http://othes.univie. ac.at/18168/1/2012-02-01_0868071.pdf; 12/12/2019.

Ben-Rafael, Eliezer y Miriam Ben-Rafael (2019): Multiple Globalizations. Linguistic Landscapes in World-Cities, Leiden: Brill.

Ben-Rafael, Eliezer, Elana Shohamy, Muhammad Hasan Amara y Nira Trumper-Hecht (2006): «Linguistic Landscape as Symbolic Construction of the Public Space: The Case of Israel», en Durk Gorter (ed.), Linguistic Landscape: A New Approach to Multilingualism, Clevedon: Multilingual Matters, 7-30.

Ben-Rafael, Eliezer, Elana Shohamy y Monica Barni (2010): «Introduction: An Approach to an "Ordered Disorder"», en Elana Shohamy, Eliezer Ben-Rafael y Monica Barni (eds.), Linguistic Landscape in the City, Bristol: Multilingual Matters, XI-XxviII.

Benítez Sierra, María (2014): La lengua inglesa en la publicidad española: el sector de las revistas de moda (Tesis de Licenciatura), Valladolid: Universidad de Valladolid. URL: http://uvadoc. uva.es/handle/10324/6279; 10/9/2019.

Calvet, Louis-Jean (1999): Pour une écologie des langues du monde, Paris: Plon.

Campetella, Luciano (2019): «Lengua(s), regulación urbana e imaginarios en tensión: los nombres de las vías de circulación en el paisaje lingüístico de Bahía Blanca», III Congreso de la Delegación Argentina de la Asociación de Lingüistica y Filología de América Latina, La Plata: Universidad Nacional de La Plata-ALFAL.

Coluzzi, Paolo (2012): «Multilingual Societies vs Monolingual States: The Linguistic Landscape in Italy and Brunei Darussalam», en Durk Gorter, Heiko F. Marten y Luk Van Mensel (eds.), Minority Languages in the Linguistic Landscape, Basingstoke: Palgrave Macmillan, 225-242.

Delgado Álvarez, Alberto (2005): «Los anglicismos en la prensa escrita costarricense», Káñina xxIx: 89-99. URL: https://revistas.ucr.ac.cr/index.php/kanina/article/view/4658; 03/7/2019.

Duché Mónaco, Laura et al. (2019): «Paisaje urbano y políticas lingüísticas en Bahía Blanca (II). Distribución y uso de las lenguas preferidas en el ámbito comercial de Bahía Blanca: consideraciones ideológico-lingüísticas», IX Encuentro Internacional de Investigadores de Politicas Lingüisticas, Rosario: Universidad Nacional de Rosario-Asociación de Universidades Grupo Montevideo.

Edelman, Loulou (2009): "What's in a name? Classification of proper names by language», en Elana Shohamy y Durk Gorter (eds.), Linguistic Landscape: Expanding the Scenery, Abingdon: Routledge, 141-154.

FERnÁndez Juncal, Carmen (2019): «Paisaje lingüístico urbano y rural: parámetros de caracterización», Cultura, Lenguaje y Representación xxi: 41-56. URL: http://www.e-revistes.uji.es/ index.php/clr/article/view/3585; 10/9/2019.

Fontanella de Weinberg, María Beatriz (1979a): Dinámica social de un cambio lingüistico. La reestructuración de las palatales en el español bonaerense, México: Universidad Nacional Autónoma de México. 
Fontanella de Weinberg, María Beatriz (1979b): La asimilación lingüistica de los inmigrantes. Mantenimiento y cambio de lengua en el sudoeste bonaerense, Bahía Blanca: Universidad Nacional del Sur.

Franco-Rodríguez, José Manuel (2009): «Interpreting the linguistic traits of linguistic landscapes as ethnolinguistic vitality: Methodological approach", Revista Electrónica de Lingüistica Aplicada 8: 1-15. URL: http://www.aesla.org.es/ojs/index.php/RAEL/article/view/146; 03/7/2019.

Gerding Salas, Constanza, Mary Fuentes Morrison y Gabriela Kotz Grabole (2012): «Anglicismos y aculturación en la sociedad chilena», Onomázein 25: 139-162. URL: http://onomazein.letras.uc.cl/Articulos/25/7_Gerding.pdf; 03/7/2019.

Goddard, Angela (2002): The Language of Advertising. Written Texts, 2. ${ }^{a}$ ed., London: Routledge.

Hipperdinger, Yolanda (2016): «El contacto como constante. Indagaciones sobre la coexistencia interlingüística en la Argentina», en Efthimía Pandís Pavlakis, Haralambos Symeonidis, Slobodan Pajović, Dimitrios Drosos y Viktoria Kritikou (eds.), Estudios y homenajes hispanoamericanos IV, Madrid: Ediciones del Orto, 149-158.

Hipperdinger, Yolanda (2018): «Coexistencia interlingüística en un paisaje lingüístico urbano. Español y otras lenguas en denominaciones comerciales de Bahía Blanca (Argentina)», Itinerarios 27: 193-216. URL: http://itinerarios.uw.edu.pl/wp-content/uploads/2018/07/11_ Yolanda-Hipperdinger.pdf; 12/12/2019.

LANDRY, Rodrigue y Richard Bourhis (1997): «Linguistic landscape and ethnolinguistic vitality: An empirical study», Journal of Language and Social Psychology 16 (1): 23-49.

LEIMgruber, Jakob (2019): «Montreal's linguistic landscape: Instances of top-down and bottom-up language planning», en Mónica Castillo Lluch, Rolf Kailuweit y Claus Pusch (eds.), Linguistic Landscape Studies: The French Connection, Freiburg im Breisgau: Rombach, 163-174.

Martínez Ibarra, Francisco (2016): «Spanish and Valencian in contact: A study on the linguistic landscape od Elche», en Sandro Sessarego y Fernando Tejedo-Herrero (eds.), Spanish Language and Sociolinguistic Analysis, Amsterdam-Philadelphia: John Benjamins, 135-153.

Medina López, Javier (1991): «Los anglicismos: a propósito de los rótulos publicitarios», Lexis xv (1): 119-128. URL: http://revistas.pucp.edu.pe/index.php/lexis/article/view/8374; 10/9/2019.

Monacci, Gustavo (1988): «Inmigración», en Félix Weinberg (dir.), Historia del sudoeste bonaerense, Buenos Aires: Plus Ultra, 205-227.

Myers-Scotton, Carol (1993a): Social Motivations for Codeswitching. Evidence from Africa, Oxford: Clarendon Press.

Myers-Scotton, Carol (1993b): Duelling Languages. Grammatical Structure in Codeswitching, Oxford: Clarendon Press.

Oostdyk, Patricia y Alicia ZAngLa (2019): «La presencia de otras lenguas en dos enclaves comerciales de la ciudad de Bahía Blanca", III Congreso de la Delegación Argentina de la Asociación de Lingüistica y Filología de América Latina, La Plata: Universidad Nacional de La Plata-ALFAL.

Orsi, Laura (2013): «Estereotipos, rasgos dialectales y variedades próximas», en Ana Fernández Garay, Marisa Censabella y Marisa Malvestitti (eds.), Lingüistica amerindia. Contribuciones y perspectivas, Buenos Aires: Universidad de Buenos Aires, 225-236.

Pons Rodríguez, Lola (2011): «Hispanoamérica en el paisaje lingüístico de Sevilla», Itinerarios 13: 97-127. URL: http://itinerarios.uw.edu.pl/wp-content/uploads/2014/11/07-rodriguez. pdf; 03/7/2019. 
Prapobratanakul, Chariya (2016): «Inside the Shop Names: Hybridity, Language Awareness and Globalization in the Linguistic Landscape of a Local Commercial Neighborhood in Bangkok», Manusya: Journal of Humanities 22: 26-37. URL: http://www.arts.chula. ac.th/-manusya/journal/index.php/manusya/issue/view/46; 10/9/2019.

Reyes Padilla, Víctor (2009): Anglicismos difundidos por la prensa y la publicidad: descripción y análisis lingüistico (tesis de Licenciatura), Lima: Universidad Mayor de San Marcos. URL: http://cybertesis.unmsm.edu.pe/handle/cybertesis/956; 10/9/2019.

Robles Ávila, Sara (2014): «Lectura y escritura del mensaje comercial: los extranjerismos de los sectores publicitarios de la tecnología de la información y de las comunicaciones», Álabe 10: 1-18. URL: http://revistaalabe.com/index/alabe/article/view/250; 03/7/2019.

Romero, José Luis (1963): A History of Argentine Political Tought, Stanford: Stanford University Press.

Rusnaningtias, Erlita (2019): «Multilingualism and mobility: Defining borders within Surabaya city through the linguistic cityscape», en Thor Kerr et al. (eds.), Urban Studies: Border and Mobility, London: Taylor \& Francis Group, 145-150.

Schlick, Maria (2003): «The English of shop signs in Europe», English Today 19 (1): 3-17.

Scollon, Ron y Suzie Wong Scollon (2003): Discourses in Place. Language in the Material World, London: Routledge.

Shang, Guowen y Libo Guo (2016): «Linguistic landscape in Singapore: what shop names reveal about Singapore's multilingualism», International Journal of Multilingualism 14 (2): 1-19.

Sнонамy, Elana y Durk Gorter (2009): «Introduction», en Elana Shohamy y Durk Gorter (eds.), Linguistic Landscape. Expanding the Scenery, New York: Taylor \& Francis, 1-10.

Toranzos, Romina (2014): Mantenimiento y cambio de lengua: el quechua entre inmigrantes bolivianos residentes en Bahía Blanca (tesis de Licenciatura), Bahía Blanca: Universidad Nacional del Sur. URL: http://repositoriosdigitales.mincyt.gob.ar/vufind/Record/RIDH_97b348b dd54cfe5008bb1b92af720556; 10/9/2019.

Van Mensel, Luk, Mieke Vandenbroucke y Robert Blackwood (2016): «Linguistic landscapes», en Ofelia García, Nelson Flores y Massimiliano Spotti (eds.), Oxford Handbook of Language and Society, Oxford: Oxford University Press, 423-449.

WANG, Jingjing (2013): «Linguistic Landscape in China: A Case Study of Shops Signs in Beijing», Studies in Literature and Language 6 (1): 40-47. URL: http://www.cscanada.net/index.php/ sll/article/view/j.sll.1923156320130601.1449; 03/7/2019. 